\title{
LA PERSONA INVESTIGADORA DEL PATRIMONIO HISTÓRICO-EDUCATIVO COMO CERNEDORA EN LA SOCIEDAD DE LA INFORMACIÓN: DE LA INFOXICACIÓN HACIA CONOCIMIENTO
}

\author{
Alazne González Santana \\ Universidad del País Vasco/Euskal Herriko Unibertsitatea, Dpto. de Teoría e Historia de la \\ Educación \\ Grupo de Investigación GARAIAN
}

\section{Resumen}

El concepto de historia del patrimonio histórico-educativo ha ido cambiando acorde con la aparición de nuevas formas de comunicarnos. Hemos pasado de estar en archivos nacionales o autonómicos para conseguir documentos, a poder hacerlo desde la comodidad de nuestro hogar a través de unos simples clics. A pesar de ello, esta suerte de aventura sólo puede llevarse a buen término cuando aprendamos a ser investigadores-cernedores. Cuando aprendamos a separar con nuestro cedazo la información veraz, presumible de poder erigirse en conocimiento científico, de aquella infoxicada que distorsiona y llena de ruidos nuestras pesquisas como personas historiadoras.

\section{Palabras clave: PATRIMONIO HISTÓRICO-EDUCATIVO; SOCIEDAD DE LA INFOR- MACIÓN; SOCIEDAD DEL CONOCIMIENTO; PATRIMONIO AUDIOVI- SUAL; TIC}

\section{THE RESEARCHER OF EDUCATIONAL- HISTORICAL HERITAGE AS SIFTER IN THE INFORMATION SOCIETY: FROM INFOXICATION TO KNOWLEDGE}

\section{Abstract}

The concept of history and historical heritage of education has changed in compliance with new ways of communication. We have passed from national or regional archives in search of documents, to be able to get them in the comfort of our home through a few simple clicks. However, this adventure can be carried out successfully only when we learn to be researcher-sifters. When we learn to separate our sieve truthful information, presumably erected power in scientific knowledge, that is infoxicated and distorted, surrounding with noise our inquiries as historian researchers.

Keywords: HISTORICAL AND EDUCATIONAL HERITAGE; INFORMATION SOCIETY; KNOWLEDGE SOCIETY; AUDIO-VISUAL HERITAGE; ICT

González Santana, Alazne. 2015. “La persona investigadora del patrimonio histórico-educativo como cernedora en la Sociedad de la Información: de la infoxicación hacia conocimiento". AusArt 3 (2): 153161. DOI: 10.1387/ausart.15950

\section{AUSART}


La figura de la persona investigadora en Ciencias Sociales, y en especial, en el ámbito del patrimonio histórico-educativo (PHE) se somete día a día a nuevos retos. Si hace apenas un par de décadas su labor era el de recorrer los recovecos arquitectónicos de archivos institucionales, bibliotecas varias, además de legajos fotocopiados que podían cederle colegas de profesión o benefactores anónimos; en la actualidad, los profesionales que se dedican al estudio del PHE deben adoptar una nueva figura que hace poco menos de medio siglo antes hubiera resultado entre quijotesca y cómica: la de personas cernedoras.

A pesar de que la Galaxia Gutenberg (McLuhan 1998) hace tiempo que entró en colisión con la Galaxia 1.0 y después con la 2.0 (Costa 2010), en el mundo de la historiografía y la museística de la educación parecía resistir ese crash audiovisual, electrónico y binario en el que nos hallamos sumidos irremediablemente en la actualidad. Este artículo, surge, por lo tanto, con la pretensión de reflexionar sobre el cambio sustantivo que el investigador del PHE ha de desempeñar en una sociedad infoxicada, en este Chernobill de la información que se ha convertido la Sociedad, que añadiría Paul Virilio (Ramonet 2002). No ha de obviarse que "el exceso de información nos ciega y nos hace sentir la ilusoria sensación de que mucha información e inmediata es sinónimo de veracidad" (González 2014, 73), cuestión que ya sugería el escritor Ray Bradbury en la mitad de los años 50 en su célebre novela distópica Fahrenheit 451. Otro escritor distópico, Huxley (2004), recordó dos décadas después que el ser humano tenía un apetito infinito por las distracciones.

No hay duda, al hilo de lo que afirman Virilio (1997) u otros autores (Esteban Ortega 2011), que las TIC fragmentan el totum informativo. No obstante, habría que ver en qué grado y de qué manera la descentralización y democratización del grueso de la información ayuda a los historiadores del PHE a desempeñar su labor.

\section{EL PATRIMONIO HISTÓRICO-EDUCATIVO EN LA SOCIEDAD DEL CONOCIMIENTO}

Es innegable es que gracias a Internet el museo físico puede transmutarse en el museo imaginario de Malraux, en un museo sin paredes. Es más, gracias al tejido-red (knit network) (Castells 2006), podemos crear redes de museos unificados permitiendo a cualquier usuario e investigador el acceso a las 
colecciones y servicios de la institución museal desde cualquier dispositivo conectado a la Red (ver Figura 1).

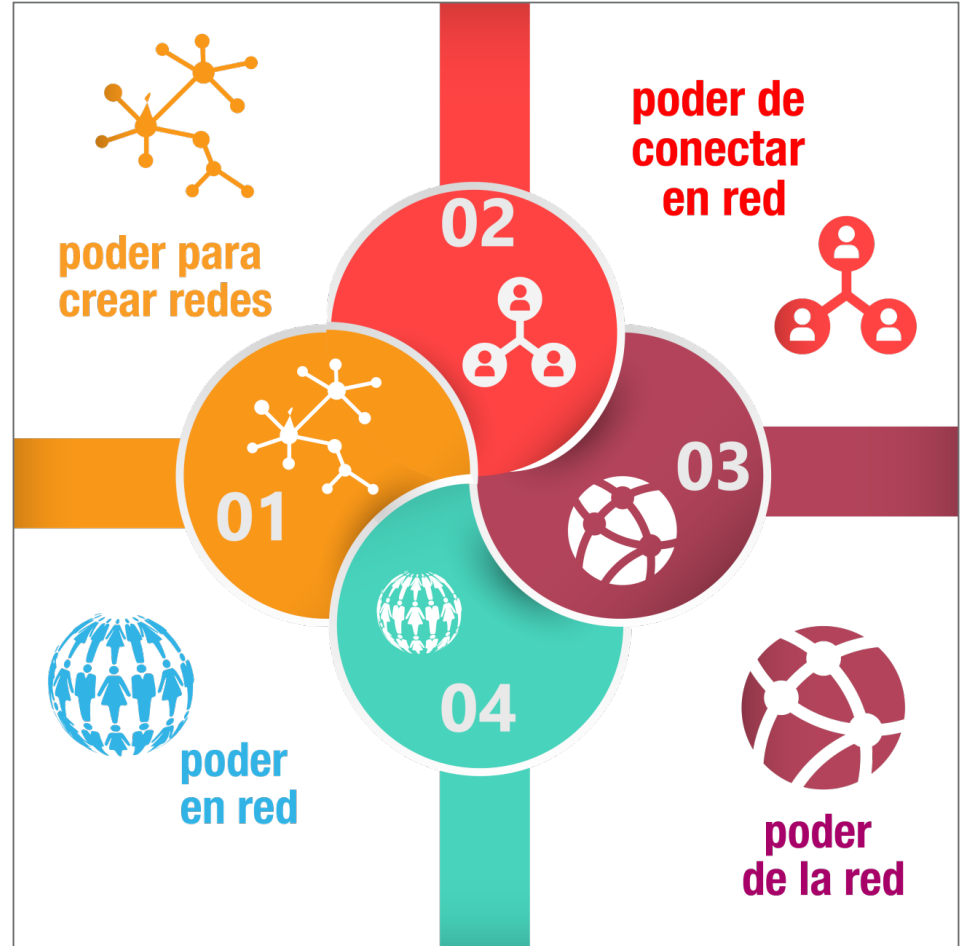

Figura 1. Infografía de las cuatro formas de poder de la red según Castells Fuente: Basado en Castells (2009, 72). Fuente de las imágenes: Freepik; Flaticon y Network por Brennan Novak from The Noun Project bajo licencia CC-BY-SA'1.

Pero tal y como se comentaba antes, la manera de ver, abordar e investigar $\mathrm{PHE}$ ha ido transmutándose a ritmo de caracol. De hecho, no ha sido hasta finales del s. XX cuando el movimiento del PHE en España se ha renovado y ha tomado en consideración los movimientos museísticos de historia del arte etc. Han sido cuatro los factores básicos que han permitido que la investigación del PHE se actualice y vaya en consonancia con la Sociedad de Información, tal y como señala Ruiz Berrio (2006, 273):

1. El auge de la Nueva Museología como "movimiento científico y técnico de influencia mundial" (ver Figura 2).

2. Los nuevos planteamientos pedagógicos que ponen el énfasis en el educando y no en el docente, a saber, se pone énfasis en el proceso de aprendizaje Vs. el de la instrucción. Gracias a esta nueva 
mirada pedagógica, los museos organizarán sus actividades en función del público visitante y el punto de vista de estos.

3. El surgimiento de la Nueva Historia de la Educación que, gracias a las microhistorias e intrahistorias (Carreño 2008, Rabazas y Ramos 2010, Ruiz Berrio 2002), se rompe con el dogma de una historia universal para centrarse en otro tipo de historias. Todas ellas, a priori, más pequeñas, pero que por otra parte empoderan y dan voz a colectivos que antes pasaron desapercibidos para la Historia Clásica de la Educación centrada en el macrosistema e ignorando los microsistemas que nutren al meso y macrosistema.

4. Y finalmente, las Tecnologías de la Información y de la Comunicación (TIC). En opinión de Ruiz Berrio (2006) las TIC son una vía importante hacia la información y hacia una democratización y descentralización de la información.

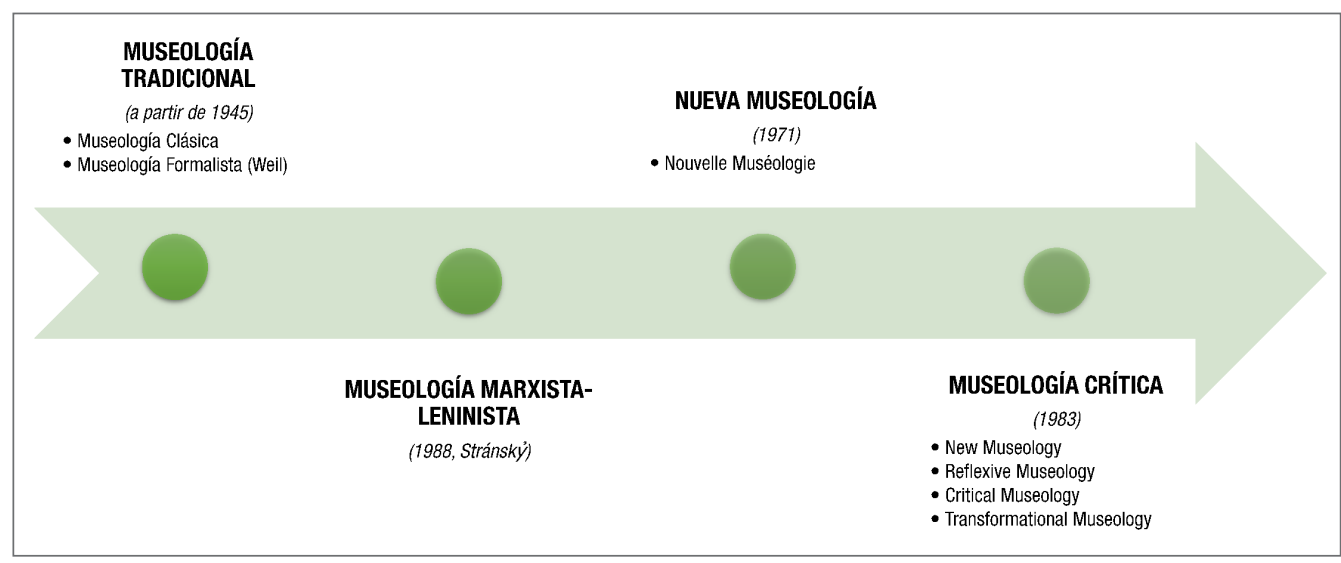

Figura 2. Evolución de los planteamientos teóricos de la museología.

Fuente: Elaborado a partir de Hernández (2006) y Lorente (2012).

Hace poco más de una década Mattelart clasificaba a los países según el grado de acceso a la información que tuvieran: inforicos/infopobres (Ramonet 2002). Esta clasificación sólo es válida para una Sociedad de la Información, donde cualquier información sea tomada como veraz. En la actualidad, sin embargo, ya no sirve únicamente con saber encontrar la información en literatura gris, bases de datos especializadas, aprender el uso de booleanos... Sino que el investigador del PHE ha de ser lo suficientemente competente como para comparar informaciones, pasarlas por su cedazo metodológico y 
elegir las más relevantes y de mayor calidad (Fottorino 2010; Duart y Mengual Andrés 2014).

La persona investigadora-cernedora ha de considerar la Sociedad como un espacio de Conocimiento, para lo cual ha de adquirir la "capacidad para identificar, producir, tratar, transformar, difundir y utilizar la información con vistas a crear y aplicar los conocimientos necesarios para el desarrollo humano." (UNESCO 2005, 29). Ha de sumir en las sombras la bomba continua de datos que nos arroja la red, diseñando y rediseñando nuestro pensamiento en base al contexto de nuestras necesidades tal y como nos aconsejan hacer Moravec (2011) o Umberto Eco (en Fottorino 2010).

\section{EL CEDAZO, ESE GRAN OLVIDADO}

En la orden universal de la Declaración de Quebec celebrada en 1984 por la ICOM $(1984,1)$, ya se tenía claro que la historiografía y el estudio del patrimonio debía orientarse hacia la sinergia con la sociedad glocal y el conocimiento:

"En el mundo contemporáneo [...] la museología debe ampliar sus objetivos, más allá de su papel y funciones tradicionales de identificación, de conservación y de educación, para que su acción pueda incidir mejor en el entorno humano y físico.

Para conseguir este objetivo [...] la museología recurre cada vez más a la interdisciplinariedad, a los nuevos métodos de comunicación, comunes a todo tipo de acción cultural, y a los nuevos métodos de gestión capaces de integrar a los usuarios."

En una sociedad democrática y equitativa no se ha de abogar única y expresamente por el derecho a la información, sino que se ha de defender a capa y espada el derecho al conocimiento. La nueva brecha digital no está en lo que otrora decía Mattelart entre inforicos e infopobres, sino en infocernedores Vs. Infoglotones. Cuesta $(2007,67)$ recuerda que únicamente desde la escucha del silencio es posible conocer:

"Esta obsesión por capturarlo todo, envolverlo en soporte digital y ponerlo a disposición del usuario (incluidas las escuelas), con- 
forme a la actualidad "cultura del testigo» (Baer, 2004), al cual se pretende la utopía negativa de evitar el olvido olvidando descomunales sarcófagos de imágenes y sonidos. La cantidad no se transforma en calidad. Lo educativo, el auténtico deber de la memoria, es captar, como proponía Benjamin, el todo en la luminosa humildad de lo pequeño. Recordar sólo, o casi, es posible desde el silencio."

De hecho, parece mentira que las palabras de Foucault $(2010,1065)$ sigan de plena actualidad, y que de hecho, más que nunca, se tienda a digitalizar y subir cualquier tipo de material sin ton ni son a Internet, sin pasar por el debido cedazo al miríada de datos que diariamente se suben a Internet.

"Museos y bibliotecas son heterotopías en las que el tiempo no deja de amontonarse y de encaramarse a la cima de sí mismo, mientras en el siglo XVII, incluso hasta finales del mismo, los museos y las bibliotecas eran la expresión de una elección individual. En cambio, la idea de acumularlo todo, la idea de constituir una especie de archivo general, la voluntad de encerrar en un lugar todas las épocas, todas las formas, todos los gustos, la idea de constituir un lugar de todos los tiempos que esté por sí mismo fuera del tiempo y sea inaccesible a su mordedura, proyecto de organizar así una especie de acumulación perpetua e indefinida del tiempo en un lugar que no cambie de sitio, todo eso pertenece a nuestra modernidad. El museo y la biblioteca son heterotopías propias de la cultura occidental del siglo XIX."

Uno de los grandes problemas a los que se enfrenta las personas que investigan sobre el PHE es, precisamente, la proliferación de numerosos bancos de datos audiovisuales que se han ido creando en este último lustro. Teniendo en cuenta que hasta entonces conseguir fuentes documentales audiovisuales se antojaba una tarea digna de Don Quijote, por la complejidad que entrañaba encontrar documentos fotográficos que no sirvieran únicamente para ilustrar texto (Burke 2005), puede resultar disparatado afirmar que, a veces, el exceso de información lo que hace es confundir al investigador, máxime cuando las fotografías o vídeos con los que se encuentra no cuentan con una ficha técnica lo suficientemente rica que permita hacer un análisis en profundidad (Kossoy 2014).

En muchas ocasiones nos encontramos con bases de datos institucionales que únicamente indican la procedencia de la fotografía, vídeo o audio pero 
que no indica en qué soporte original se había tomado el objeto: si se trata de una fotografía impresa en una postal; si es un vídeo en Beta, V2000 etc. (ver Figura 3).

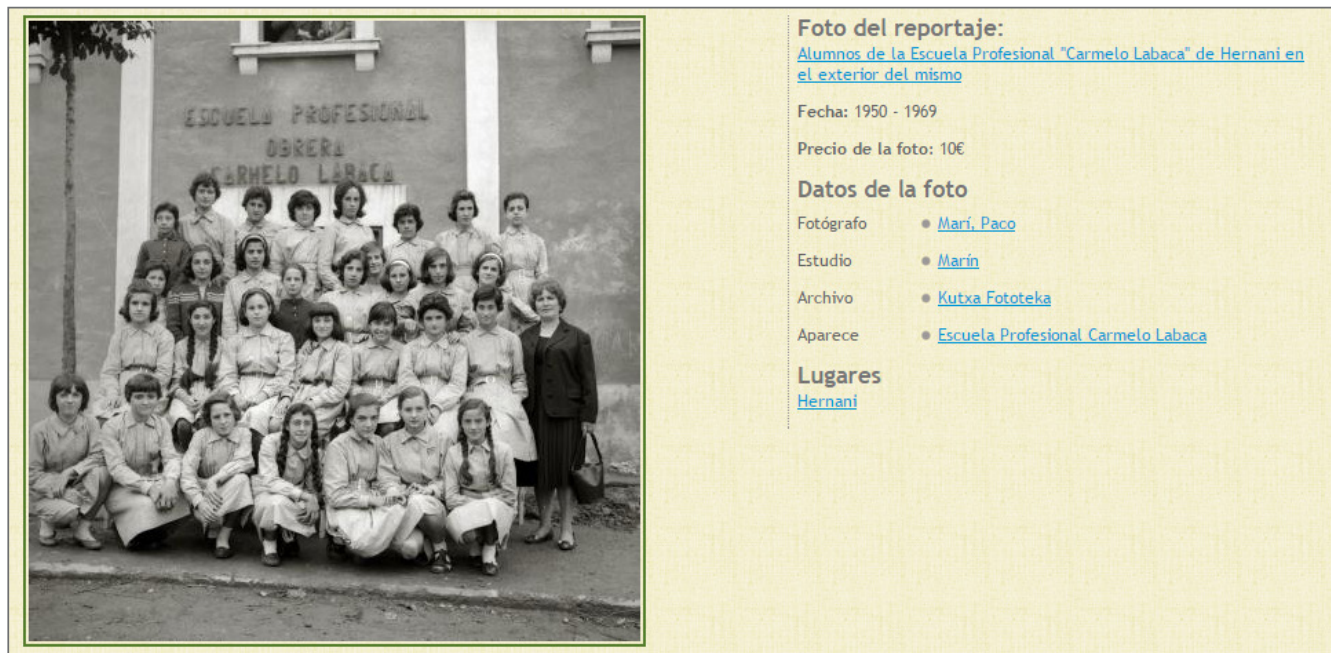

Figura 3. Muestra de una foto de la Kutxateka.

Fuente: < https://www.kutxateka.com/index.php/Detail/Object/Show/object_id/327623/lang/es_ES>

\section{CONCLUSIONES}

No obstante, esta suerte de aventura sólo puede llevarse a buen término cuando aprendamos a ser personas cernedoras. En otras palabras, que, siendo conscientes de nuestra misión histórico-educativa, aprendamos sin más dilaciones a separar con nuestro cedazo de historiadores la información veraz, presumible de poder erigirse en conocimiento científico, de aquella infoxicada que distorsiona y llena de ruidos nuestras pesquisas como personas historiadoras. Para ello, nos debemos fortalecer de fuentes bibliográficas fidedignas versus pseudoinformaciones de dudoso origen. Siguiendo estos pasos seremos capaces de dejar a un lado el ruido que genera la red de redes, Internet, para poder centrarnos en ciertos autores y fuentes a las que poder escuchar y atender con dedicación y veracidad.

Dice Tanizaki en El Elogio a la Sombra que le "gustaría resucitar, al menos en el ámbito de la literatura, ese universo de sombras que estamos disipando..." Añade, además, que también le "gustaría ampliar el alero de ese edificio llamado «literatura», oscurecer sus paredes, hundir en la sombra lo que resulta 
demasiado visible y despojar su interior de cualquier adorno superfluo." (Tanizaki 2014, 94-5). Desde este artículo se aboga por elogiar la sombra no sólo en la literatura, sino en el universo de las artes y las ciencias gracias al empleo de nuestra metacognición, la ayuda de Booleanos y el ejercitar nuestro radar de detección de ruido (pseudoinfomaciones) gracias al arte del tamiz.

\section{Referencias}

Area Moreira, Manuel \& Teresa Ribeiro Pessoa. 2012. "De lo sólido a lo líquido: Las nuevas alfabetizaciones ante los cambios culturales de la Web 2.0". Comunicar 19(38): 13-20. doi: 10.3916/C38-2012-02-01

Bradbury, Ray. (1953) 2001. Fahrenheit 451. 2a ed. Barcelona: Debolsillo; Plaza \& Janés

Burke, Peter. 2005. Visto y no visto: El uso de la imagen como documento histórico. Traducción de Teófilo de Lozoya. Barcelona: Crítica

Canes Garrido, Francisco. 2010. "Objetos escolares y museos de la educación". En El Patrimonio histórico-educativo: Su conservación y estudio, Julio Ruiz Berrio, ed., 31-62. Madrid: Biblioteca Nueva

Carreño Rivero, Myriam. 2008. "Los nuevos museos de educación, un movimiento internacional". Encounters on Education 9(Fall): 75-91. http://library.queensu.ca/ojs/index.php/ encounters/article/view/1769/2210

Castells Oliván, Manuel. 2006. "Informacionalismo, redes y sociedad red: Una propuesta teórica." En La Sociedad Red: una visión global, Manuel Castells y Francisco Muñoz de Bustillo, eds., 27-75. Madrid: Alianza

- 2009. Comunicación y poder. Madrid: Alianza

Costa Solà-Segalés, Joan. 2010. "Ecología de la comunicación e interacción social". En Pensar la Publicidad IV (2):17-24

Cuesta Fernández, Raimundo. 2007. Los deberes de la memoria en la educación. Barcelona: Octaedro

Duart Montoliu, Josep María \& Santiago Mengual Andrés. 2014. Impacto de la sociedad del conocimiento en la universidad y en la comunicación científica. Relieve 20(2): 1-12. doi: 10.7203/relieve.20.2.4343

Eco, Umberto. 2010. "En el futuro, la educación deberá enseñar a comparar sitios Web". Por Eric Fottorino. Ñ Revista de Cultura 368, 16 oct. www.revistaenie.clarin.com/literatura/educacion-debera-ensenar-comparar-Web 0 352764926.html

Esteban Ortega, Joaquín, ed. 2011. La aceleración: velocidad, cultura y comunicación en los espacios urbanos contemporáneos. Seminarium. Valladolid: Univ. Europea Miguel de Cervantes

Foucault, Michel. (1967) 2010. "Espacios diferentes." En Obras esenciales, 1059-65. Barcelona: Paidós

González Santana, Alazne. 2014. "Las noticias de actualidad como medio para superar la ceguera de la sobreexposición informativa". En "Actualidad como Recurso Educativo", número especial Comunicación y Pedagogía 271-272: 73-8 
Hernández Hernández, Francisca. 2006. Planteamientos teóricos de la museología, Biblioteconomía y administración cultural. Gijón: Trea

Huxley, Aldous. (1932) 2004. Brave new world: and Brave new world revisited. New York: Harper-Collins

ICOM [Consejo Internacional de Museos]. 1984. "Declaración de Québec: Principios básicos de una nueva museología". Acceso 23 marzo 2014. www.sernageomin.cl/Museo Geologico/ documentos/nueva museologia quebec.pdf

Lorente Lorente, Jesús Pedro. 2012. Manual de historia de la museología. Manuales de Museística, Patrimonio y Turismo Cultural. Gijón: Trea

Mattelart, Armand. 2002. "La nueva comunicación". En La post-televisión: multimedia, Internet y globalización económica, Ignacio Ramonet, ed., 33-46. Barcelona: Icaria

McLuhan, Marshall. (1962) 1998. La galaxia Gutenberg. Barcelona: Círculo de Lectores

Moravec, John W., ed. 2011. Knowmad Society. Dallas TX: Education Futures

Morin, Edgar. 1999. Los siete saberes necesarios para la educación del futuro. Traducción de Mercedes Vallejo-Gómez. París: UNESCO. http://www.virtual.unal.edu.co/cursos/humanas/mtria edu/2021082/und1/anexos/sietesaberes.pdf

Nietzsche, Friedrich. (1874) 1999. Sobre la utilidad y el perjuicio de la historia para la vida : II intempestiva. Traducido por Germán Cano. Madrid: Biblioteca Nueva

Rabazas Romero, Teresa, y Sara Ramos Zamora. 2010. "Patrimonio histórico-educativo de España. Museología y museografía". En El patrimonio histórico-educativo: Su conservación y estudio, Julio Ruiz Berrio, coord., 169-200. Madrid: Biblioteca Nueva

Ramonet Míguez, Ignacio, ed. 2002. La post-televisión: Multimedia, Internet y globalización económica. Antrazyt 180. Barcelona: Icaria

Ruiz Berrio, Julio. 2002. "Los museos de educación y la historia de la Educación". En La memoria y el deseo: cultura de la escuela y educación deseada, Agustín Escolano y José María Hernández Díaz, eds., 43-65. Valencia: Tirant Lo Blanch

- 2006. "Historia y museología de la Educación: Despegue y reconversión de los museos pedagógicos". Historia de la Educación 25: 271-290. http://revistas.usal.es/index.php/02120267/article/view/11182

Tanizaki, Junichiro. (1933) 2014. El elogio de la sombra. 32a ed. Madrid: Siruela

UNESCO. 2005. "Hacia las sociedades del conocimiento". Informe Mundial de la UNESCO. http://unesdoc.unesco.org/images/0014/001419/141908s.pdf

Virilio, Paul. 1997. El cibermundo, la politica de lo peor. Entrevista con Philippe Petit, traducción de Mónica Poole. Madrid: Cátedra

Notas

${ }^{1}$ Reconocimiento - Compartir Igual (by-sa): Se permite el uso comercial de la obra y de las posibles obras derivadas, la distribución de las cuales se debe hacer con una licencia igual a la que regula la obra original. 